\title{
Reoperations on the pulmonary autograft and pulmonary homograft after the Ross procedure: An update on the German Dutch Ross Registry
}

\author{
Efstratios I. Charitos, MD, ${ }^{a}$ Johanna J. M. Takkenberg, MD, ${ }^{b}$ Thorsten Hanke, MD, ${ }^{a}$ Armin Gorski, MD, ${ }^{c}$ \\ Cornelius Botha, MD, ${ }^{\mathrm{d}}$ Ulrich Franke, MD, ${ }^{\mathrm{e}}$ Ali Dodge-Khatami, MD,${ }^{\mathrm{f}}$ Juergen Hoerer, $\mathrm{MD},{ }^{\mathrm{g}}$ \\ Rudiger Lange, MD, ${ }^{\mathrm{g}}$ Anton Moritz, MD,${ }^{\mathrm{h}}$ Katharina Ferrari-Kuehne, MD ${ }^{\mathrm{i}}$ Roland Hetzer, MD, \\ Michael Huebler, MD, ${ }^{\mathrm{j}}$ Ad J. J. C. Bogers, MD, ${ }^{\mathrm{b}}$ Ulrich Stierle, MD, ${ }^{\mathrm{a}}$ Hans-Hinrich Sievers, MD, ${ }^{\mathrm{a}}$ and \\ Wolfgang Hemmer, $\mathrm{MD}^{\mathrm{k}}$
}

Objectives: Reinterventions after the Ross procedure are a concern for patients and treating physicians. The scope of the present report was to provide an update on the reinterventions observed in the large patient population of the German-Dutch Ross Registry.

Patients and Methods: From 1988 to 2011, 2023 patients (age, $39.05 \pm 16.5$ years; male patients, 1502; adults, 1642) underwent a Ross procedure in 13 centers. The mean follow-up was $7.1 \pm 4.6$ years (range, 0 - 22 years; 13,168 patient-years).

Results: In the adult population, 120 autograft reinterventions in 113 patients (1.03\%/patient-year) and 76 homograft reinterventions in 67 patients $(0.65 \%$ /patient-year) and, in the pediatric population, 14 autograft reinterventions in 13 patients ( $0.91 \%$ /patient-year) and 42 homograft reinterventions in 31 patients $(2.72 \% /$ patient-year) were observed. Of the autograft and homograft reinterventions, $17.9 \%$ and $21.2 \%$ were performed because of endocarditis, respectively. The subcoronary technique in the adult population resulted in significantly superior autograft durability (freedom from autograft reintervention: $97 \%$ at 10 years and $91 \%$ at 12 years; $P<.001$ ). The root replacement technique without root reinforcement (hazard ratio, $2.4 ; 95 \%$ confidence interval, 1.4-4.1) and the presence of pure aortic insufficiency preoperatively (hazard ratio, 2.3 ; $95 \%$ confidence interval, 1.5-3.5) were statistically significant predictors for a shorter time to reoperation. The center volume had a significant influence on the long-term results. The freedom from homograft reoperation for the adults and pediatric population was $97 \%$ and $87 \%$ at 5 years and $93 \%$ and $79 \%$ at 12 years, respectively $(P<.001)$, with younger recipient and donor age being significant predictors of a shorter time to homograft reoperation.

Conclusions: The autograft principle remains a valid option for young patients requiring aortic valve replacement. The risk of reoperation depends largely on the surgical technique used and the preoperative hemodynamics. Center experience and expertise also influence the long-term results. Adequate endocarditis prophylaxis might further reduce the need for reoperation. (J Thorac Cardiovasc Surg 2012;144:813-23)

Although the Ross procedure has been shown to offer numerous advantages, including freedom from lifelong anticoagulation, survival comparable to that of the general

\footnotetext{
From the University of Luebeck, ${ }^{\mathrm{a}}$ Luebeck, Germany; Erasmus Medical Center, ${ }^{\mathrm{b}}$ Rotterdam, The Netherlands; University of Wuerzburg, ${ }^{\mathrm{c}}$ Wuerzburg, Germany; Bodensee Heart Center, ${ }^{\mathrm{d}}$ Konstanz, Germany; Robert Bosch Hospital, ${ }^{\mathrm{e}}$ Stuttgart, Germany; University of Hamburg, ${ }^{\mathrm{f}}$ Hamburg, Germany; German Heart Center, ${ }^{\mathrm{g}}$ Munich, Germany; Johann Wolfgang Goethe University, ${ }^{\text {h }}$ Frankfurt, Germany; University of Jena, ${ }^{i}$ Jena, Germany; German Heart Center, ${ }^{j}$ Berlin, Germany; and Sana Stuttgart, ${ }^{\mathrm{k}}$ Stuttgart, Germany.

Disclosures: Authors have nothing to disclose with regard to commercial support.

Read at the 92nd Annual Meeting of The American Association for Thoracic

Surgery, San Francisco, California, April 28-May 2, 2012.

Received for publication April 23, 2012; revisions received May 24, 2012; accepted

for publication July 9, 2012; available ahead of print Aug 10, 2012

Address for reprints: Efstratios I. Charitos, MD, Department of Cardiac and Thoracic

Vascular Surgery, University of Luebeck, Ratzeburger Allee 160, Luebeck 23562,

Germany (E-mail: efstratios.charitos@gmail.com).

0022-5223/\$36.00

Copyright (c) 2012 by The American Association for Thoracic Surgery

http://dx.doi.org/10.1016/j.jtcvs.2012.07.005
}

population, superior quality of life, unrestricted daily activities, and normal aortic valve hemodynamics, ${ }^{1-10}$ the incidence of reoperation remains a concern. Together with the technical complexity of the procedure, the need for reoperations, on the autograft, the homograft, or both, has been the cornerstone of debate of whether the Ross procedure should be performed, especially in adult patients.

The aim of the present study was to present in detail the incidence of, reasons for, outcomes of, and factors that influence, reoperation after the Ross procedure observed in the multicenter German-Dutch Ross Registry. Although a detailed analysis of the adult and pediatric populations is presented, the main focus of the present study was the adult patient. The information presented could facilitate decision making when informing young patients with aortic valve disease before surgical intervention and could serve as a basis for comparing the outcomes after the 


\section{Abbreviations and Acronyms \\ $\mathrm{SC}=$ subcoronary \\ $\mathrm{RR}=$ root replacement without additional root reinforcement \\ $\mathrm{RR}+\mathrm{R}=$ root replacement with additional root reinforcement}

Ross procedure with that of alternative therapeutic options for the treatment of aortic valve disease.

\section{PATIENTS AND METHODS}

The German-Dutch Ross Registry collects data from 13 departments of cardiac surgery, retrospectively for 1988 to 2001 and prospectively from 2002 onward (clinical trial no. NCT00708409). For the purposes of the present study, the study database was frozen in August 2011 and included 2023 patients.

The operating surgeon at each center determined the surgical technique (subcoronary $[\mathrm{SC}]$ or root replacement with $[\mathrm{RR}+\mathrm{R}]$ or without $[\mathrm{RR}]$ additional root reinforcement procedures). Reinforcement interventions in the $R R+R$ group were performed either in the annulus only $(n=394)$, the sinotubular junction only $(n=35)$, or at both levels $(n=214)$. A total of 30 patients who underwent the root inclusion (miniroot) technique were included in the SC group to create a group with all native root-preserving procedures. The details of the operative techniques and the reasons for including the root inclusion technique patients in the SC group have been reported previously. ${ }^{1,2,6}$ All the patients provided informed consent; the local ethics committee approved the study; all authors had full access to, and take full responsibility for, the integrity of the data.

All indications for the primary operation and for all reoperations were in accordance with the 2008 guidelines. ${ }^{11}$ Clinical follow-up examinations were performed at discharge and yearly thereafter. The reporting and analysis of the outcomes and major adverse cardiac and cerebrovascular events were according to published guidelines. ${ }^{12}$

The present report focused on the need for cardiac, valve-related reinterventions on the autograft or homograft after the Ross procedure. Cardiac nonvalvular, as well as cardiac, valvular, non-Ross-related interventions, are not presented. Cases of pacemaker implantation within 14 days after the Ross procedure were not included in the present study and have been previously reported. ${ }^{1,6}$ A Ross reintervention was defined as any surgical or interventional procedure performed after the initial Ross procedure on the autograft or homograft. A Ross reoperation was defined as a surgical session that included at least 1 Ross reintervention on the autograft or homograft, or both $(1,1$, and 2 reinterventions, respectively) and could include concomitant interventions to other cardiac structures.

The adult and pediatric population of the Registry were analyzed and reported separately. The cutoff point of 16 years was chosen to differentiate the adult and pediatric populations, because at this age, the patients were regarded from a surgical viewpoint as adults and the technical aspects of the procedure were those of the adult population.

Frequencies are given as absolute numbers and percentages. Continuous data are expressed as the mean \pm standard deviation. The actuarial estimates of freedom from reoperation events were made using the KaplanMeier method. The instantaneous risk of reoperation is presented as the smoothed instantaneous probability that a patient will require reoperation within the interval $(t, t+d t)$ provided the patient was not censored until the beginning of $t .^{13-15}$ To identify the predictive variables for a shorter time to reoperation on the autograft or homograft, we performed univariate analyses using the Cox proportional hazard regression model. Multivariate Cox proportional hazard models were used to confirm whether significant $(P<.10)$ univariate predictors persisted in the presence of other preoperative variables. The following factors were analyzed as potential risk factors for autograft or homograft reoperation: age, year of surgery, gender, presence of co-morbidities (eg, diabetes, hypertension, renal failure, coronary artery disease, pulmonary disease, peripheral vascular disease), previous cardiac surgery, preoperative hemodynamics, aortic valve morphology, center experience (number of operated patients per center), year of surgery, and homograft donor parameters (eg, diameter, donor recipient age and blood group mismatch).

Given the data obtained to date from the German-Dutch Ross Registry and our understanding of the risk of autograft and homograft reintervention that patients undergoing the Ross procedure face, we attempted to extrapolate the estimated risk of reoperation for a Ross patient up to 70 years of age according to the patient's age at the initial Ross procedure, taking into consideration the probability of survival up to 70 years old. The survival of the Ross patients was assumed to be similar to that of the German general population (data available from: https://www.destatis.de), because several studies have failed to show excess mortality for the Ross population compared with that of the general population..$^{3,6,7,15}$ For the calculation of the estimated risk of reoperation with the SC and RR techniques, the hazards for autograft and homograft reoperation were assumed to be independent, and the Ross-related reoperation hazard rate was evaluated as the sum of the hazard rate for the autograft and homograft reoperation functions. The homograft hazard rate in the adults was assumed to be linear (see Figure 2). For the SC technique, a constant autograft reoperation hazard rate was assumed for the period after 17 years of follow-up $\left(h_{S C}(t \geq 17)=0.014\right)$. For the RR group, significant evidence was seen for an increase in the autograft hazard rate with time (see Figure 3), ${ }^{1,6}$ and an exponential hazard rate was assumed $h_{R R}(t)=0.01+0.01 e^{\frac{t}{5.9}}$ (see Figure 3).

\section{RESULTS}

The patient characteristics and operative data are presented in Table 1. Completeness of follow-up for the outcomes presented in the present study was $96 \%$.

A detailed listing of the reoperations and reinterventions observed in the total population, stratified by technique and population subgroup, is presented in Table 2 . The reoperative mortality rate is also listed in Table 2 .

The choice of autograft or homograft replacement material used in the respective reinterventions is listed in Table 3.

The actuarial estimates for freedom for autograft, homograft, and combined reoperation for the subpopulations of the present study are listed in Table 4 . The survival estimates for the adult and pediatric populations are also listed in Table 4. No significant difference was seen between the survival of the adult Ross population and that of the ageand gender-matched general population $(P=.3)$. However, the survival of the pediatric population was significantly inferior to that of the age- and gender-matched general population $(P<.0001)$.

The results of the multivariate Cox proportional hazards model for a shorter time to autograft and homograft reoperation in the adult population are listed in Table 5.

Freedom from autograft, homograft, or combined reoperation in the population groups and the technique subgroups are displayed in Figures 1 to 5. 
TABLE 1. Patient characteristics and operative data

\begin{tabular}{|c|c|c|c|c|c|c|}
\hline & \multirow[b]{2}{*}{ Total } & \multirow[b]{2}{*}{ Adults } & \multirow[b]{2}{*}{ Pediatric } & \multicolumn{3}{|c|}{ Adults } \\
\hline & & & & SC & $\mathbf{R R}$ & $\mathbf{R} \mathbf{R}+\mathbf{R}$ \\
\hline Patients (n) & 2023 & 1760 & 263 & 771 & 346 & 643 \\
\hline \multicolumn{7}{|l|}{ Follow-up (y) } \\
\hline Mean & 7.1 & 7.1 & 6.9 & 7 & 9.1 & 6.1 \\
\hline Range & $0-22.4$ & $0-22.4$ & $0-21.8$ & $0-18.5$ & $0-22.4$ & $0-15$ \\
\hline Age (y) & $39 \pm 16.5$ & $43.7 \pm 12.0$ & $8 \pm 5.2$ & $45.2 \pm 11.3$ & $37.6 \pm 12.6$ & $45.1 \pm 11.3$ \\
\hline Male gender & $1502(74 \%)$ & $1315(75 \%)$ & $187(71 \%)$ & $585(76 \%)$ & $253(73 \%)$ & 477 (74\%) \\
\hline \multicolumn{7}{|l|}{ Age group (y) } \\
\hline$<16$ & $263(13 \%)$ & $(0 \%)$ & $263(100 \%)$ & & & \\
\hline $16-40$ & $661(33 \%)$ & $661(38 \%)$ & & $255(33 \%)$ & $198(57 \%)$ & $208(33 \%)$ \\
\hline $41-60$ & $1019(50 \%)$ & $1019(58 \%)$ & & $470(61 \%)$ & $141(41 \%)$ & $408(63 \%)$ \\
\hline$>60$ & $80(4 \%)$ & $80(4 \%)$ & & $46(6 \%)$ & $7(2 \%)$ & $27(4 \%)$ \\
\hline \multicolumn{7}{|l|}{ Predominant aortic hemodynamics } \\
\hline Regurgitation & $469(23 \%)$ & $423(24 \%)$ & $46(17 \%)$ & $197(26 \%)$ & $87(25 \%)$ & $139(22 \%)$ \\
\hline Stenosis & $457(23 \%)$ & $408(23 \%)$ & $49(19 \%)$ & $143(19 \%)$ & $79(23 \%)$ & $186(29 \%)$ \\
\hline Combined & $1048(52 \%)$ & $894(51 \%)$ & $154(59 \%)$ & $419(54 \%)$ & $172(50 \%)$ & $303(47 \%)$ \\
\hline \multicolumn{7}{|l|}{ Aortic valve type } \\
\hline Bicuspid & $1254(62 \%)$ & $1105(63 \%)$ & $149(56 \%)$ & $532(69 \%)$ & $189(55 \%)$ & $384(60 \%)$ \\
\hline Tricuspid & $480(24 \%)$ & $410(23 \%)$ & $70(27 \%)$ & $170(22 \%)$ & $110(32 \%)$ & $130(20 \%)$ \\
\hline Other & $175(9 \%)$ & $157(9 \%)$ & $18(7 \%)$ & $34(4 \%)$ & $23(7 \%)$ & $100(16 \%)$ \\
\hline Unknown & $111(5 \%)$ & $85(5 \%)$ & $26(10 \%)$ & $35(5 \%)$ & $22(6 \%)$ & $28(4 \%)$ \\
\hline Atrial fibrillation & $16(1 \%)$ & $16(1 \%)$ & $0(0 \%)$ & $11(1 \%)$ & $2(1 \%)$ & $3(0 \%)$ \\
\hline \multicolumn{7}{|l|}{ Concomitant procedures $(\mathrm{n})$} \\
\hline Total & $884(44 \%)$ & $813(46 \%)$ & $71(27 \%)$ & $333(43 \%)$ & $99(29 \%)$ & $381(59 \%)$ \\
\hline CABG & $102(5 \%)$ & $100(6 \%)$ & $2(1 \%)$ & $30(4 \%)$ & $19(5 \%)$ & $51(8 \%)$ \\
\hline Previous cardiac interventions (n) & $299(15 \%)$ & $158(9 \%)$ & $141(54 \%)$ & $40(5 \%)$ & $40(12 \%)$ & $57(9 \%)$ \\
\hline \multicolumn{7}{|l|}{ Circulatory arrest } \\
\hline Patients (n) & $106(5 \%)$ & $97(6 \%)$ & $9(3 \%)$ & $62(8 \%)$ & $62(18 \%)$ & $30(5 \%)$ \\
\hline Mean $\pm \mathrm{SD}$ & $18.2 \pm 10.8$ & $17.4 \pm 9$ & $39.7 \pm 29.3$ & $17.9 \pm 4$ & $17.9 \pm 4$ & $13.2 \pm 4.6$ \\
\hline Range & $2-72$ & $2-64$ & $15-72$ & $11-33$ & $11-33$ & $3-23$ \\
\hline \multicolumn{7}{|l|}{ CPB time (min) } \\
\hline Mean \pm SD & $189.1 \pm 47.6$ & $191.2 \pm 45.6$ & $175.7 \pm 57.1$ & $211 \pm 35.2$ & $211 \pm 35.2$ & $170.7 \pm 41.9$ \\
\hline Range & $61-685$ & $71-685$ & $61-495$ & $71-433$ & $71-433$ & $95-482$ \\
\hline \multicolumn{7}{|l|}{ Cross-clamp time (min) } \\
\hline Mean \pm SD & $146.2 \pm 36.1$ & $150.4 \pm 34.9$ & $119.7 \pm 31.8$ & $172.2 \pm 34.1$ & $172.2 \pm 34.1$ & $135.1 \pm 24.9$ \\
\hline Range & $17-293$ & $38-293$ & $17-265$ & $43-293$ & 43-293 & $79-258$ \\
\hline In-hospital ( $<30 \mathrm{~d})$ mortality & $29(1.4 \%)$ & $20(1.1 \%)$ & $9(3.4 \%)$ & $8(1 \%)$ & $2(0.6 \%)$ & $10(1.6 \%)$ \\
\hline
\end{tabular}

\section{DISCUSSION}

The main scope of the present study was to provide a detailed presentation of the reasons, incidence, results, and outcomes of reoperations on the autograft or homograft after the Ross procedure in the adult and pediatric populations of the German-Dutch Ross Registry. The incidence of other major adverse cardiac and cerebrovascular events has been previously reported. ${ }^{6}$ The information provided in the present study might facilitate patient-physician discussions before aortic valve interventions and outline patient expectations after the Ross procedure regarding the probability, incidence, and outcomes of reoperations. The present results could also serve as a basis for a comparison of the outcomes after the Ross procedure with those after other novel or conventional therapeutic options for the treatment of aortic valve disease.

Although the first Ross procedure was performed as an SC transplant, ${ }^{16}$ the technical complexity of this procedure eventually led to the development of the RR technique, which provided, at least for the early to midterm, satisfactory results. ${ }^{17}$ The initial enthusiasm for the RR Ross procedure soon waned, after several reports of the increased incidence of reoperations because of autograft dilatation starting 7 to 10 years after the initial procedure. ${ }^{18-25}$ Research on the modes of failure of the pulmonary autograft has shown a technique-specific pattern of autograft failure. ${ }^{1}$ In the RR technique, the main mode of autograft failure seems to be nonstructural valve 
TABLE 2. Reinterventions observed in German-Dutch Ross Registry

\begin{tabular}{|c|c|c|c|c|}
\hline & & Technique & & \\
\hline & RR & $\mathbf{R} \mathbf{R}+\mathbf{R}$ & SC & Total \\
\hline Adults & & & & \\
\hline Patients with Ross-related reoperation ( $\%$ of total) & $64(18.5 \%)$ & $39(6.1 \%)$ & $53(6.9 \%)$ & $156(8.9 \%)$ \\
\hline Follow-up (y) & & & & \\
\hline Mean \pm SD & $9.1 \pm 5.4$ & $6.1 \pm 3.9$ & $7 \pm 4.3$ & $7.1 \pm 4.5$ \\
\hline Range & $0-22.4$ & $0-15$ & $0-18.5$ & $0-22.4$ \\
\hline Cumulative follow-up (pt-y) & 2925.3 & 3481.7 & 5218.7 & $11,625.7$ \\
\hline Ross-related reoperations & 69 & 43 & 62 & 174 \\
\hline Reoperation mortality (n) & 0 & 1 & 5 & 6 \\
\hline Ross-related reinterventions & 79 & 45 & 72 & 196 \\
\hline Reoperation type & & & & \\
\hline Autograft & 44 & 27 & 27 & 98 \\
\hline Homograft & 15 & 14 & 25 & 54 \\
\hline Combined & 10 & 2 & 10 & 22 \\
\hline Autograft reinterventions & 54 & 29 & 37 & 120 \\
\hline Endocarditis & 1 & 11 & 11 & 23 \\
\hline SVD & 4 & 7 & 20 & 31 \\
\hline NSVD & 49 & 10 & 6 & 65 \\
\hline Technical & 1 & 1 & 0 & 2 \\
\hline Homograft reinterventions & & & & 76 \\
\hline SVD & & & & \\
\hline Stenosis & & & & 44 \\
\hline Regurgitation & & & & 10 \\
\hline NSVD & & & & 6 \\
\hline Endocarditis & & & & 16 \\
\hline Pediatric & & & & \\
\hline Patients with Ross-related reoperation ( $\%$ of total) & $28(16.6 \%)$ & $7(18.9 \%)$ & $6(10.5 \%)$ & $41(15.6 \%)$ \\
\hline Follow-up (y) & & & & \\
\hline Mean \pm SD & $6.4 \pm 5.7$ & $8.5 \pm 2.8$ & $7.2 \pm 4.3$ & $6.9 \pm 5.2$ \\
\hline Range & $0-21.8$ & $0.2-13.5$ & $0-16.4$ & $0-21.8$ \\
\hline Cumulative follow-up (pt-y) & 933.1 & 306.4 & 303.3 & 1542.7 \\
\hline Ross-related reoperations & 37 & 8 & 9 & 54 \\
\hline Reoperation mortality (n) & 0 & 0 & 0 & 0 \\
\hline Ross-related reinterventions & 38 & 9 & 9 & 56 \\
\hline Reoperation type & & & & \\
\hline Autograft & 9 & 2 & 1 & 12 \\
\hline Homograft & 27 & 5 & 8 & 40 \\
\hline Combined & 1 & 1 & 0 & 2 \\
\hline Autograft reintervention & 10 & 3 & 1 & 14 \\
\hline NSVD & 10 & 3 & 0 & 13 \\
\hline Endocarditis & 0 & 0 & 1 & 1 \\
\hline Homograft reinterventions & & & & 42 \\
\hline SVD & & & & \\
\hline Stenosis & & & & 25 \\
\hline Regurgitation & & & & 7 \\
\hline NSVD & & & & 1 \\
\hline Endocarditis & & & & 9 \\
\hline
\end{tabular}

$N S V D$, Nonstructural valve deterioration; $p t-y$, patient-year; $R R$, root replacement without additional root reinforcement; $R R+R$, root replacement with additional root reinforcement; $S C$, subcoronary; $S V D$, structural valve deterioration; $S D$, standard deviation.

deterioration (Table 2), mainly because of dilatation of the unsupported pulmonary root under systemic pressure, leading to progressive loss of valve coaptation and the development of autograft insufficiency. However, when the autograft is implanted as an SC transplant, the main cause of failure is leaflet-related degeneration (structural valve deterioration; Table 2).

Although some prominent series have been published with excellent results after the RR Ross procedure, ${ }^{23,25,26}$ the high failure rate after the first decade has initiated 
TABLE 3. Choice of replacement material at reintervention

\begin{tabular}{|c|c|c|c|c|c|c|c|}
\hline & Biologic & Homograft & Mechanical & Repair & Valve sparing & Catheter & Unknown/not coded \\
\hline \multicolumn{8}{|l|}{ Adults } \\
\hline Autograft (n) & 26 & 8 & 45 & 19 & 7 & 1 & 14 \\
\hline \multicolumn{8}{|c|}{ Age at reoperation $(\mathrm{y})$} \\
\hline Mean \pm SD & $47.3 \pm 12.9$ & $38.5 \pm 12.5$ & $32.0 \pm 12.5$ & $44.0 \pm 10.8$ & $39.7 \pm 9.79$ & & \\
\hline Range & $21.9-64.9$ & $18.9-52.0$ & $16.2-66.0$ & $20.2-58.3$ & $23.4-50.9$ & & \\
\hline $\mathrm{RR}$ & 5 & 4 & 35 & 3 & 1 & 1 & 5 \\
\hline $\mathrm{RR}+\mathrm{R}$ & 9 & 3 & 1 & 9 & 6 & & 1 \\
\hline $\mathrm{SC}$ & 12 & 1 & 9 & 7 & & & 8 \\
\hline Homograft & 6 & 39 & 1 & 2 & & 16 & 12 \\
\hline \multicolumn{8}{|l|}{ Pediatric } \\
\hline Autograft & 0 & 4 & 3 & 2 & 2 & 0 & 3 \\
\hline $\mathrm{RR}$ & & 3 & 3 & & 1 & & 3 \\
\hline $\mathrm{RR}+\mathrm{R}$ & & 1 & & 1 & 1 & & \\
\hline $\mathrm{SC}$ & & & & 1 & & & \\
\hline Homograft & 1 & 19 & 2 & 3 & & 11 & 6 \\
\hline
\end{tabular}

The decision for the type of prosthesis at reoperation was the result of a thorough informed consent process after taking into consideration the recommendations and patientspecific needs and wishes. $R R$, Root replacement without additional root reinforcement; $R R+R$, root replacement with additional root reinforcement; $S C$, subcoronary; $S D$, standard deviation.

either a switch back to the original SC technique or a search for technical modifications to prevent root dilatation. ${ }^{1,6-8,17,27,28}$ During the past decade, several groups have reported satisfactory results with the modified RR Ross procedure, using autograft root reinforcement with various techniques and materials in an attempt to stabilize the tissue and the areas of the aortic root that have been shown to dilate and result in progressive autograft insufficiency late after the Ross procedure. ${ }^{1,17,27,28}$ This change has also been observed in the German-Dutch Ross Registry, with most active centers having switched now to either the SC technique or to RR with aggressive reinforcement of the autograft annulus or sinotubular junction, or both. ${ }^{1} \mathrm{~A}$ small increase in the risk of reoperation in the $R R+R$ group after the first decade has been observed (Figure 3). However, to date, no statistically significant difference in the freedom from autograft reoperation can be observed between the $R R+R$ and $S C$ groups. Because $R R+R$ is a relatively new technique, only a few $(<6 \%)$ of patients have completed a follow-up period of longer than 12 years. Therefore, reliable conclusions about the second decade could not be made for the $R R+R$ group.

Endocarditis remains a significant cause of reoperation after the Ross procedure. Although it was initially believed that the Ross procedure, by using only biologic (autologous and allogenic) material, might be resistant to postoperative endocarditis, data from the German-Dutch Ross registry have shown that almost $20 \%$ of all interventions on the autograft or homograft were performed because of endocarditis (Table 2). This should be of interest to the treating physician and for the follow-up of Ross patients, because aggressive endocarditis prophylaxis could lead to a reduction in the incidence of endocarditis and, thus, the need for reoperations. The understanding that endocarditis can occur in patients with autologous and allograft material, together with a high clinical suspicion, is required to diagnose nonfulminant autograft or homograft endocarditis and prevent valve deterioration. This is especially important for Ross patients, because 2 valves are at risk and because the latest guidelines are more restrictive regarding the use of antibiotic prophylaxis. ${ }^{29}$

Several groups have demonstrated that patients with pure aortic insufficiency with or without aortic dilatation seem to have a much greater incidence of autograft deterioration. $^{30-36}$ Although the data from the German-Dutch Ross Registry have shown that although pure aortic insufficiency is an independent predictor for a shorter time to reoperation, this effect (Table 5) appears to be milder than that reported in other series. ${ }^{33,35,36}$ Also, its effect seems to be more pronounced with the RR technique without active reinforcement. Although many patients with pure aortic insufficiency currently undergo aortic valve reconstruction, we believe that aortic insufficiency should not be regarded as a contraindication to the Ross procedure. Similarly, the presence of a bicuspid aortic valve did not have any influence on the incidence of autograft reoperation.

In the pediatric population, the effect of the surgical technique on autograft durability was less pronounced. Autograft reoperations in the first decade were rare (Figure 1$)^{37}$ but could become necessary after the first decade. Most reoperations and reinterventions in the pediatric population were for homograft deterioration (Figure 2 and Table 2). ${ }^{38}$ Also, younger homograft donor and recipient age appeared to lead to significantly inferior homograft durability (Table 5). Catheter reinterventions on the homograft might reduce the need for conventional reoperation 
TABLE 4. Actuarial estimates for freedom from autograft, homograft, or any Ross reintervention (with and without endocarditis) and survival estimates in adult and pediatric population

\begin{tabular}{|c|c|c|}
\hline Variable & $5 y$ & $12 y$ \\
\hline \multicolumn{3}{|c|}{ Freedom from reoperation } \\
\hline \multicolumn{3}{|c|}{ Endocarditis included } \\
\hline \multicolumn{3}{|l|}{ Autograft } \\
\hline \multicolumn{3}{|l|}{ Adult } \\
\hline $\mathrm{SC}$ & $97 \%(96-98)$ & $91 \%(88-95)$ \\
\hline RR & $97 \%(95-99)$ & $82 \%(76-88)$ \\
\hline $\mathrm{RR}+\mathrm{R}$ & $96 \%(94-98)$ & $91 \%(86-96)$ \\
\hline Pediatric & $98 \%(96-100)$ & $95 \%(91-99)$ \\
\hline \multicolumn{3}{|l|}{ Homograft } \\
\hline Adult & $97 \%(97-98)$ & $93 \%(91-95)$ \\
\hline Pediatric & $87 \%(82-92)$ & $79 \%(72-87)$ \\
\hline \multicolumn{3}{|l|}{ Combined } \\
\hline \multicolumn{3}{|l|}{ Adult } \\
\hline SC & $95 \%(94-97)$ & $88 \%(84-92)$ \\
\hline RR & $95 \%(92-97)$ & $77 \%(71-83)$ \\
\hline $\mathrm{RR}+\mathrm{R}$ & $94 \%(92-96)$ & $87 \%(81-93)$ \\
\hline Pediatric & $86 \%(81-91)$ & $76 \%(69-84)$ \\
\hline \multicolumn{3}{|c|}{ Endocarditis excluded } \\
\hline \multicolumn{3}{|l|}{ Autograft } \\
\hline \multicolumn{3}{|l|}{ Adult } \\
\hline $\mathrm{SC}$ & $98 \%(97-99)$ & $94 \%(91-97)$ \\
\hline RR & $97 \%(95-99)$ & $82 \%(76-88)$ \\
\hline$R R+R$ & $98 \%(96-99)$ & $93 \%(88-98)$ \\
\hline Pediatric & $98 \%(96-100)$ & $95 \%(91-99)$ \\
\hline \multicolumn{3}{|l|}{ Homograft } \\
\hline Adult & $98 \%(97-99)$ & $95 \%(93-96)$ \\
\hline Pediatric & $90 \%(85-94)$ & $83 \%(90-76)$ \\
\hline \multicolumn{3}{|l|}{ Combined } \\
\hline \multicolumn{3}{|l|}{ Adult } \\
\hline $\mathrm{SC}$ & $97 \%(95-98)$ & $91 \%(87-95)$ \\
\hline RR & $95 \%(92-97)$ & $78 \%(72-84)$ \\
\hline$R R+R$ & $96 \%(94-98)$ & $90 \%(84-95)$ \\
\hline Pediatric & $89 \%(84-94)$ & $80 \%(74-88)$ \\
\hline \multicolumn{3}{|l|}{ Survival } \\
\hline Adult & $98 \%(97-99)$ & $93 \%(91-95)$ \\
\hline Pediatric & $97 \%(94-99)$ & $95 \%(91-99)$ \\
\hline
\end{tabular}

Data in parentheses are $95 \%$ confidence intervals. $R R$, Root replacement without additional root reinforcement; $R R+R$, root replacement with additional root reinforcement; $S C$, subcoronary.

(Table 3). However, the long-term performance of this therapeutic option remains unknown.

As with any operation, the major determinants of the operative outcome include not only the type and complexity of the operation itself, but also the status of the patient at surgery. During the 224 reoperations observed in the German-Dutch Ross Registry, 6 patients died of postoperative complications $(2.6 \%)$. This low reoperative mortality rate has also been observed by other groups. ${ }^{39-43}$ However, it is important to note that all these patients presented with a critical status (5 patients because of endocarditis and 1 patient for technical reasons) requiring either urgent or emergency surgery. No reoperative
TABLE 5. Multivariate Cox proportional hazard model for shorter time to autograft or homograft reoperation in adult population

\begin{tabular}{lccc}
\hline \multicolumn{1}{c}{ Variable } & HR & $\mathbf{9 5} \%$ CI & $\boldsymbol{P}$ value \\
\hline Autograft & & & \\
$\quad$ Technique & & & \\
$\quad$ SC & Baseline & & \\
$\quad$ RR+R & 1.4 & $0.8-2.3$ & .25 \\
$\quad$ RR & 2.4 & $1.4-4.1$ & .001 \\
$\quad$ Center volume & $0.998 /$ patient & $0.997-0.999$ & .001 \\
$\quad$ Preoperative hemodynamics & & & \\
$\quad$ Pure aortic regurgitation & 2.3 & $1.5-3.5$ & $<.001$ \\
Homograft & & & \\
$\quad \begin{array}{l}\text { Patient age group (y) } \\
\quad<16\end{array}$ & 5.1 & $2.1-12.4$ & $<.001$ \\
$\quad$ 16-40 & 2.2 & $0.9-5.0$ & .08 \\
$\quad$ 41-60 & Baseline & \\
$\quad>60$ & & $0.9-5.0$ & .08 \\
$\quad$ Donor age (y) & 0.975 & $0.96-0.99$ & $<.001$ \\
\hline$C I$, Confidence interval; $H R$, hazard ratio; $R R$, root replacement without additional \\
root reinforcement; $R R+R$, root replacement with additional root reinforcement; \\
$S C$, subcoronary.
\end{tabular}

mortality was observed in the patients presenting or scheduled for an elective reoperation.

In the young patient requiring aortic valve surgery, the lifetime risk of valve-related complications with mechanical valves is neither $0 \%$ nor rare. ${ }^{44-46}$ If the Ross procedure manages to bridge the young patient with aortic valve disease from an age when a conventional biologic solution is questionable (age, 20-60 years) to an age at which a biologic or even transcatheter (age, $>65-70$ years) solution is feasible, this, we believe, also constitutes a success of the Ross procedure. However, even when an

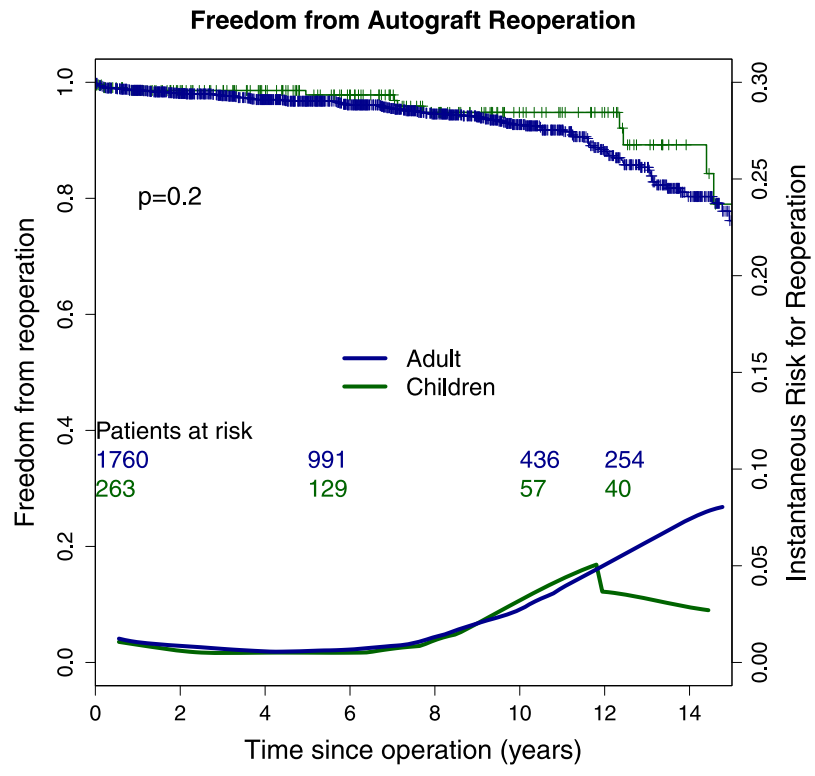

FIGURE 1. Freedom from autograft reintervention in the pediatric and adult (all techniques) population. 


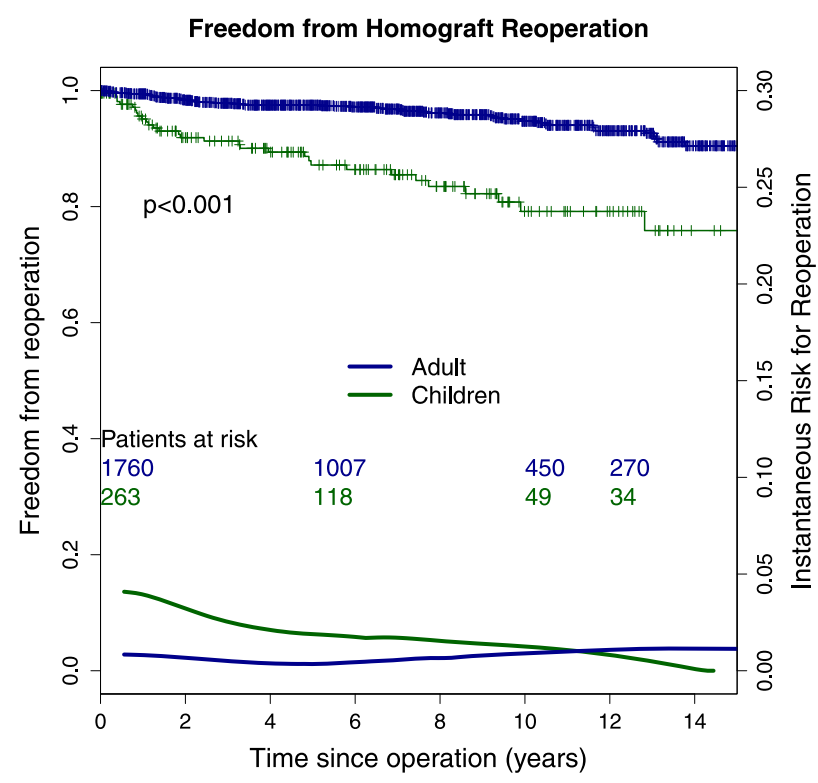

FIGURE 2. Freedom from homograft reintervention in the pediatric and adult population.

autograft reoperation becomes necessary, in about $22 \%$ of cases, the autograft can be either repaired or spared (Table 3), thus retaining some of the benefits the pulmonary autograft has to offer. Elective reoperation in the case of autograft or homograft deterioration can be performed with remarkable safety in experienced centers. Also, catheter interventions will probably reduce the incidence and the need for open conventional procedures further.

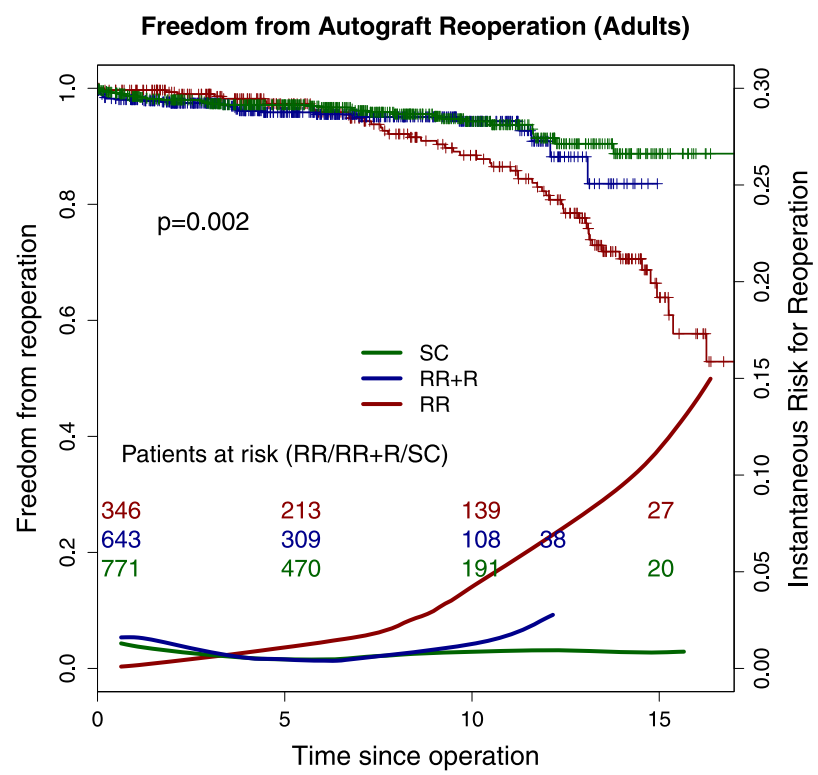

FIGURE 3. Freedom from autograft reintervention in the adult population stratified by the operative technique. $R R$, Root replacement without additional root reinforcement; $R R+R$, root replacement with additional root reinforcement; $S C$, subcoronary.

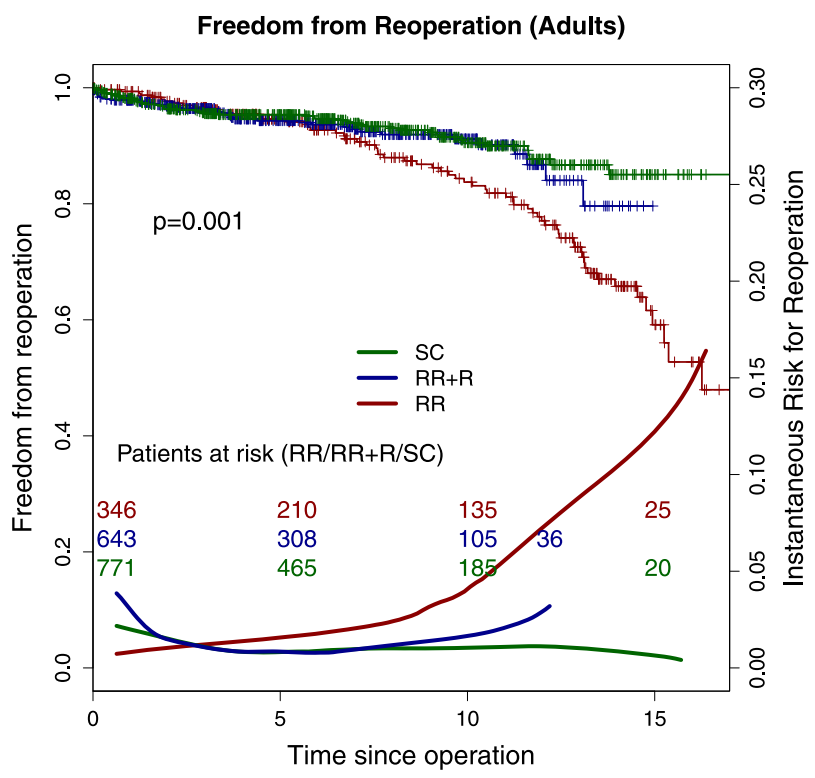

FIGURE 4. Freedom from autograft or homograft reintervention in the adult population stratified by the operative technique. $R R$, Root replacement without additional root reinforcement; $R R+R$, root replacement with additional root reinforcement; $S C$, subcoronary.

Despite all therapeutic options and modalities, even today, aortic valve replacement, remains a palliative treatment. Mechanical and biologic prostheses bring advantages and disadvantages that the patient and physician should weigh carefully before making an important, informed decision. Eventually, patients requiring aortic valve replacement face some risk of procedural or postoperative valve-related complications. From the view of the treating

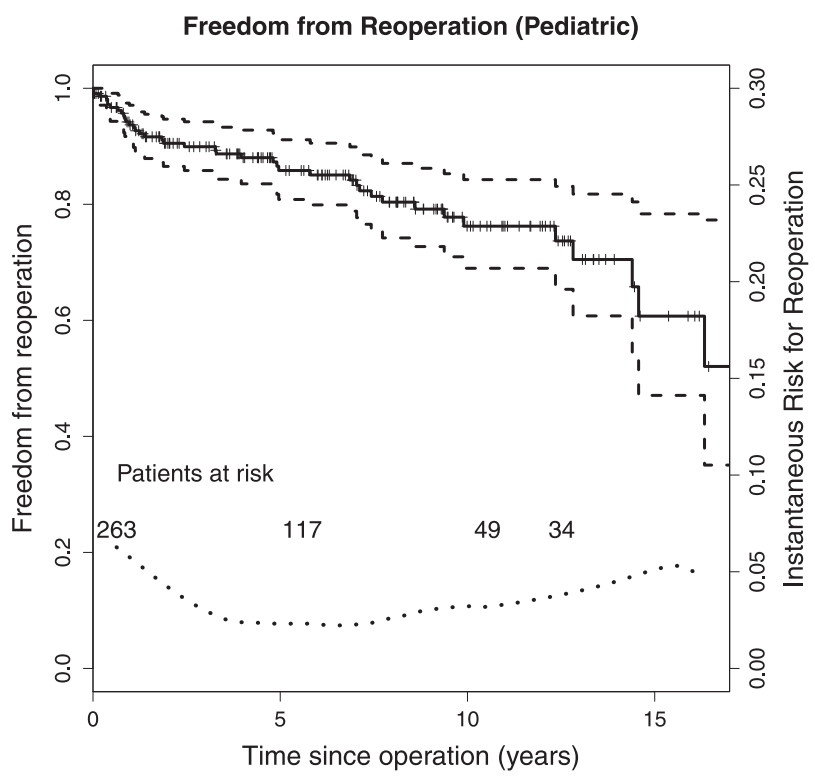

FIGURE 5. Freedom from autograft or homograft reintervention in the pediatric population. 
surgeon, and especially for the Ross procedure, the wish for risk avoidance or risk intolerance, might deny a great proportion of young patients with aortic valve disease all the benefits the Ross procedure has to offer. ${ }^{47,48}$

\section{Study Limitations}

The present study is a retrospective analysis of an ongoing nonrandomized registry. The intention of the surgeon when performing reinforcement was either to treat an underlying pathology or to prophylactically stabilize key elements of the aortic root to prevent dilatation. For the estimation of the probability of reoperation to the age of 70 years, the risk of autograft or homograft reoperation until age 70 years was extrapolated from the data obtained to date. The survival of the Ross patients was assumed to be comparable to that of the general population. Although evidence has shown that this holds true for the first 2 decades after the Ross procedure, ${ }^{3,6,7,15}$ it is unclear whether this persists beyond that point. However if the survival of Ross patients after the second decade is inferior to that of the general population, the probability of reoperation would have been even smaller owing to the competing risk of death. ${ }^{49-51}$

\section{CONCLUSIONS}

The present report has outlined the most frequently discussed complication after the Ross procedure, namely, the need for reoperation. Although we see several reasons for a focused presentation on the incidence of reoperation after the Ross procedure, one should evaluate and weigh the need for reoperations under the prism of their relative frequency and against the many benefits the Ross procedure offers to the patient. These benefits include survival comparable to that of the general population, freedom from lifelong anticoagulation, a superior quality of life, unrestricted daily activities, and normal aortic valve hemodynamics. ${ }^{3-7,10}$ According to our current knowledge and estimations, not all Ross patients will require reoperation when treated with the SC technique (Figure 6), which, at least in the period of the present study, provided the most robust longterm results.

The risk of reoperation after the Ross procedure depends largely on the surgical technique used and the preoperative hemodynamics. Also, significant research and technical modifications have been successful in progressively reducing the need for reoperation, especially in centers with experience in the treatment of young patients with aortic valve disease. Adequate endocarditis prophylaxis to prevent autograft or homograft endocarditis and increased clinical suspicion might reduce the need for reoperation further. The Ross procedure remains a valid option with many benefits and small risks for the young patient requiring aortic valve replacement.

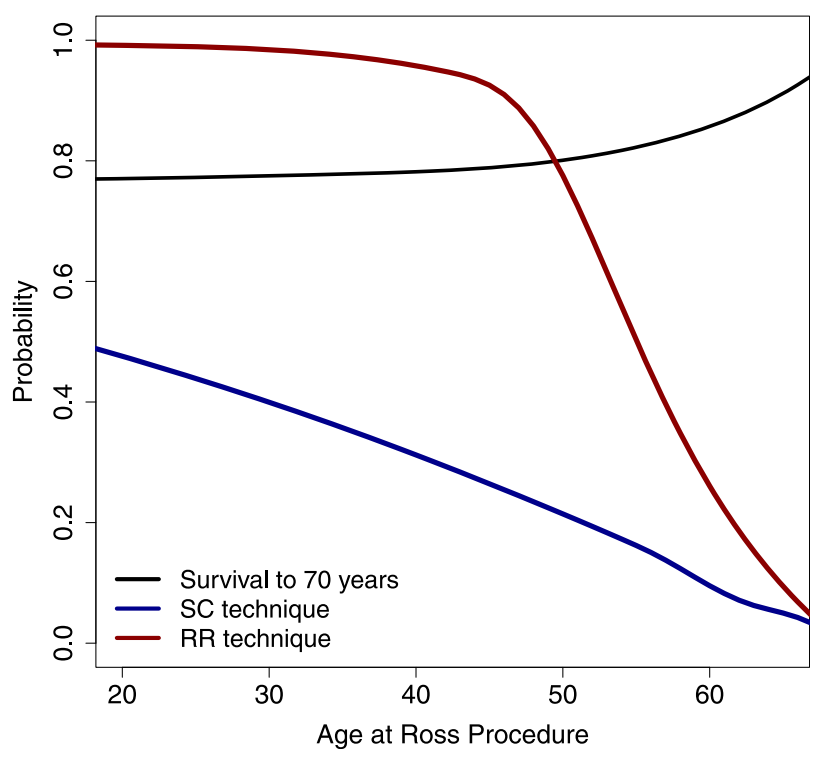

FIGURE 6. Estimation of the probability of autograft or homograft reintervention until 70 years of age according to the age at the Ross procedure for patients treated with the subcoronary $(S C)$ and root replacement $(R R)$ techniques.

\section{References}

1. Charitos EI, Hanke T, Stierle U, Robinson DR, Bogers AJ, Hemmer W, et al. Autograft reinforcement to preserve autograft function after the Ross procedure: a report from the German-Dutch Ross Registry. Circulation. 2009;120: S146-54.

2. Hanke T, Stierle U, Boehm JO, Botha CA, Matthias Bechtel JF, Erasmi A, et al. Autograft regurgitation and aortic root dimensions after the Ross procedure: the German Ross Registry experience. Circulation. 2007;116:I251-8.

3. Mokhles MM, Körtke H, Stierle U, Wagner O, Charitos EI, Bogers AJJC, et al. Survival comparison of the Ross procedure and mechanical valve replacement with optimal self-management anticoagulation therapy: propensity-matched cohort study. Circulation. 2011;123:31-8.

4. Notzold A, Droste DW, Hagedorn G, Berndt S, Kaps M, Graf B, et al. Circulating microemboli in patients after aortic valve replacement with pulmonary autografts and mechanical valve prostheses. Circulation. 1997;96:1843-6.

5. Notzold A, Huppe M, Schmidtke C, Blomer P, Uhlig T, Sievers HH. Quality of life in aortic valve replacement: pulmonary autografts versus mechanical prostheses. J Am Coll Cardiol. 2001;37:1963-6.

6. Sievers H-H, Stierle U, Charitos EI, Hanke T, Misfeld M, Matthias Bechtel JF, et al. Major adverse cardiac and cerebrovascular events after the Ross procedure: a report from the German-Dutch Ross Registry. Circulation. 2010;122:S216-23.

7. Sievers H-H, Stierle U, Charitos EI, Hanke T, Gorski A, Misfeld M, et al. Fourteen years' experience with 501 subcoronary Ross procedures: surgical details and results. J Thorac Cardiovasc Surg. 2010;140:816-22.

8. Sievers HH, Hanke T, Stierle U, Bechtel MF, Graf B, Robinson DR, et al. A critical reappraisal of the Ross operation: renaissance of the subcoronary implantation technique? Circulation. 2006;114:I504-11.

9. Sievers HH, Schmidtke C, Graf B. Hemodynamics of semilunar valves at rest and exercise at an average of more than two years after the Ross procedure. J Heart Valve Dis. 2001;10:166-70.

10. Steinbruchel DA, Hasenkam JM, Nygaard H, Riis CM, Sievers HH. Blood velocity patterns after aortic valve replacement with a pulmonary autograft. Eur J Cardiothorac Surg. 1997;12:873-5.

11. Bonow RO, Carabello BA, Kanu C, de Leon AC, Faxon DP, Freed MD, et al. ACC/AHA 2006 guidelines for the management of patients with valvular heart disease: a report of the American College of Cardiology/American Heart Association Task Force on Practice Guidelines (Writing Committee to revise the 1998 Guidelines for the Management of Patients With Valvular Heart Disease): developed in collaboration with the Society of Cardiovascular Anesthesiologists: 
endorsed by the Society for Cardiovascular Angiography and Interventions and the Society of Thoracic Surgeons. Circulation. 2006;114:e84-231.

12. Akins CW, Miller DC, Turina MI, Kouchoukos NT, Blackstone EH, Grunkemeier GL, et al. Guidelines for reporting mortality and morbidity after cardiac valve interventions. Eur J Cardiothorac Surg. 2008;135:732-8.

13. Hess KR, Serachitopol DM, Brown BW. Hazard function estimators: a simulation study. Stat Med. 1999;18:3075-88.

14. Müller HG, Wang JL. Hazard rate estimation under random censoring with varying kernels and bandwidths. Biometrics. 1994;50:61-76.

15. Charitos EI, Stierle U, Hanke T, Schmidtke C, Sievers H-H, Richardt D. Longterm results of 203 young and middle-aged patients with more than 10 years of follow-up after the original subcoronary Ross operation. Ann Thorac Surg. 2012;93:495-502

16. Ross DN. Replacement of aortic and mitral valves with a pulmonary autograft. Lancet. 1967;2:956-8.

17. Stelzer P. The Ross procedure: state of the art 2011. Semin Thorac Cardiovasc Surg. 2011;23:115-23

18. Kouchoukos NT. Should we still do the Ross operation in adults? Curr Opin Cardiol. 2011;26:94-8

19. Kouchoukos NT, Davila-Roman VG, Spray TL, Murphy SF, Perrillo JB. Replacement of the aortic root with a pulmonary autograft in children and young adults with aortic-valve disease. N Engl J Med. 1994;330:1-6.

20. Kouchoukos NT, Masetti P, Nickerson NJ, Castner CF, Shannon WD, DavilaRoman VG. The Ross procedure: long-term clinical and echocardiographic follow-up. Ann Thorac Surg. 2004;78:773-81.

21. Stelzer P. Reoperation for dilatation of the pulmonary autograft after the Ross procedure. J Thorac Cardiovasc Surg. 2002;124:417-8.

22. Klieverik LM, Takkenberg JJ, Bekkers JA, Roos-Hesselink JW, Witsenburg M, Bogers AJ. The Ross operation: a Trojan horse? Eur Heart J. 2007; 28:1993-2000.

23. Takkenberg JJ, Klieverik LM, Schoof PH, van Suylen RJ, van Herwerden LA, Zondervan PE, et al. The Ross procedure: a systematic review and meta-analysis. Circulation. 2009;119:222-8.

24. Takkenberg JJ, Zondervan PE, van Herwerden LA. Progressive pulmonary autograft root dilatation and failure after Ross procedure. Ann Thorac Surg. 1999;67: 551-3.

25. Yacoub MH, Klieverik LM, Melina G, Edwards SE, Sarathchandra P, Bogers AJ, et al. An evaluation of the Ross operation in adults. J Heart Valve Dis. 2006;15: 531-9.

26. El-Hamamsy I, Eryigit Z, Stevens L-M, Sarang Z, George R, Clark L, et al. Longterm outcomes after autograft versus homograft aortic root replacement in adults with aortic valve disease: a randomised controlled trial. Lancet. 2010;376:524-31.

27. Stelzer P. Technique and results of the modified Ross procedure in aortic regurgitation versus aortic stenosis. Adv Cardiol. 2002;39:93-9.

28. Stelzer P, Weinrauch $S$, Tranbaugh RF. Ten years of experience with the modified Ross procedure. J Thorac Cardiovasc Surg. 1998;115:1091-100.

29. Nishimura RA, Carabello BA, Faxon DP, Freed MD, Lytle BW, O'Gara PT, et al. ACC/AHA 2008 Guideline update on valvular heart disease: focused update on infective endocarditis: a report of the American College of Cardiology/American Heart Association Task Force on Practice Guidelines endorsed by the Society of Cardiovascular Anesthesiologists, Society for Cardiovascular Angiography and Interventions, and Society of Thoracic Surgeons. JAm Coll Cardiol. 2008;52:676-85.

30. David TE, Omran A, Ivanov J, Armstrong S, de Sa MP, Sonnenberg B, et al. Dilation of the pulmonary autograft after the Ross procedure. J Thorac Cardiovasc Surg. 2000;119:210-20

31. David TE, Omran A, Webb G, Rakowski H, Armstrong S, Sun Z. Geometric mismatch of the aortic and pulmonary roots causes aortic insufficiency after the Ross procedure. J Thorac Cardiovasc Surg. 1996;112:1231-9.

32. David TE, Woo A, Armstrong S, Maganti M. When is the Ross operation a good option to treat aortic valve disease? J Thorac Cardiovasc Surg. 2010;139:68-73.

33. Brown JW, Fehrenbacher JW, Ruzmetov M, Shahriari A, Miller J, Turrentine MW. Ross root dilation in adult patients: is preoperative aortic insufficiency associated with increased late autograft reoperation? Ann Thorac Surg. 2011;92:74-81

34. Brown JW, Ruzmetov M, Rodefeld MD, Mahomed Y, Turrentine MW. Incidence of and risk factors for pulmonary autograft dilation after Ross aortic valve replacement. Ann Thorac Surg. 2007;83:1781-7.

35. Ryan WH, Prince SL, Culica D, Herbert MA. The Ross procedure performed for aortic insufficiency is associated with increased autograft reoperation. Ann Thorac Surg. 2011;91:64-9.

36. Mokhles MM, Bogers AJJC, Takkenberg JJM. No Ross operation for patients with aortic regurgitation? Ann Thorac Surg. 2011;92:1156-7.
37. Hörer J, Stierle U, Bogers AJJC, Rein JG, Hetzer R, Sievers HH, et al. Re-interventions on the autograft and the homograft after the Ross operation in children Eur J Cardiothorac Surg. 2010;37:1008-14.

38. Hörer J, Hanke T, Stierle U, Takkenberg JJM, Bogers AJJC, Hemmer W, et al Homograft performance in children after the Ross operation. Ann Thorac Surg. 2009;88:609-15

39. Stulak JM, Burkhart HM, Sundt TM III, Connolly HM, Suri RM, Schaff HV, et al. Spectrum and outcome of reoperations after the Ross procedure. Circulation. 2010;122:1153-8

40. Luciani GB, Favaro A, Casali G, Santini F, Mazzucco A. Reoperations for aortic aneurysm after the Ross procedure. J Heart Valve Dis. 2005;14: 766-72.

41. Juthier F, Vincentelli A, Pinçon C, Banfi C, Ennezat PV, Maréchaux S, et al. Reoperation after the Ross procedure: incidence, management, and survival. Ann Thorac Surg. 2012;93:598-604.

42. Bekkers JA, Klieverik LMA, Raap GB, Takkenberg JJM, Bogers AJJC. Aortic root reoperations after pulmonary autograft implantation. $J$ Thorac Cardiovasc Surg. 2010;140:S58-63.

43. Pettersson GB, Subramanian S, Flynn M, Nowicki ER, Batizy LH, Svensson LG, et al. Reoperations after the Ross procedure in adults: towards autograft-sparing/ Ross reversal. J Heart Valve Dis. 2011;20:425-32.

44. van Geldorp MWA, Jamieson WRE, Kappetein AP, Ye J, Fradet GJ, Eijkemans MJC, et al. Patient outcome after aortic valve replacement with a mechanical or biological prosthesis: weighing lifetime anticoagulant-related event risk against reoperation risk. J Thorac Cardiovasc Surg. 2009;137:881-6.

45. Puvimanasinghe JPA, Takkenberg JJM, Edwards MB, Eijkemans MJC Steyerberg EW, Van Herwerden LA, et al. Comparison of outcomes after aortic valve replacement with a mechanical valve or a bioprosthesis using microsimulation. Heart. 2004;90:1172-8.

46. Grunkemeier GL, Li HH, Naftel DC, Starr A, Rahimtoola SH. Long-term performance of heart valve prostheses. Curr Probl Cardiol. 2000;25:73-154.

47. Treasure T, Hasan A, Yacoub M. Is there a risk in avoiding risk for younger patients with aortic valve disease? BMJ. 2011;342:d2466.

48. Takkenberg JJM. Invited commentary. Ann Thorac Surg. 2012;93:502.

49. Charitos EI, Stierle U, Sievers H-H. Letter by Charitos et al regarding article, "reoperation of left heart valve bioprostheses according to age at implantation." Circulation. 2012;125:e583.

50. Chan V, Malas T, Lapierre H, Boodhwani M, Lam B-K, Rubens FD, et al. Reoperation of left heart valve bioprostheses according to age at implantation. Circulation. 2011;124:S75.

51. Chan V, Malas T, Lapierre H, Boodhwani M, Lam B-K, Rubens FD, et al. Response to letter regarding article, "reoperation of left heart valve bioprostheses according to age at implantation." Circulation. 2012;125:e584.

\section{Discussion}

Dr Joseph A. Dearani (Rochester, Minn). I have no disclosures. Congratulations on the remarkable results. One of our previous AATS [American Association for Thoracic Surgery] presidents, Dr Tirone David, has acknowledged in the literature that the Ross procedure is a "complex operation and one should not be surprised that reoperations are more complicated." In contrast, standard aortic valve replacement is generally a straightforward operation that most residents would be allowed to perform. The Ross procedure in children is not controversial. In fact, it is the procedure of choice when aortic valve replacement is required. However, in adults, the low early mortality of isolated aortic valve replacement and relative good durability of bioprostheses or low incidence of thromboembolic complications with "point of care" testing in mechanical valve replacements makes the Ross procedure more controversial. My comments will focus on 3 aspects of your results in the adult age bracket, and I will ask 3 questions at the end.

First, at the initial glance, superior autograft durability with the SC implantation technique might imply that this is the technique of 
choice for Ross implantation. However, a more detailed consideration of the results demonstrated a high early mortality of $8 \%$ to $9 \%$ for reoperation in this group. In addition, when reoperation was necessary in the SC group, most required replacement and none underwent valve-sparing root replacement. Thus, although reoperation was less likely with the SC technique, the greater operative mortality associated with reoperation might temper enthusiasm to apply it more frequently.

Second, the finding of the relatively high incidence of endocarditis of either the autograft or homograft is eye opening, counterintuitive, and unexpected, particularly because some centers believe the Ross is the preferred operation for the initial treatment of aortic valve endocarditis. Although no obvious explanation is present in your report, I wonder whether the homograft preservation and preparation techniques in Europe could have potentially influenced the susceptibility to infection.

Finally, the cumulative number of reinterventions or reoperation for any given patient in the Ross population can be numerous. Your results will add to the abundant data reporting the reoperation rates after the Ross procedure. However, the reoperation rates alone do not reflect the valve disease that many Ross patients are harboring but for which they have not yet required reoperation.

Although isolated biologic or mechanical aortic valve replacement is not free of subsequent interventions, when they are required, it is more likely related to isolated aortic valve issues and complexity, and the risk of reoperation is often less than that after the Ross. With that said, your report today of low early mortality for the Ross procedure and low early mortality with reoperation and the excellent late survival make a persuasive argument for more liberal application of the Ross procedure in the young and in middle-age adults, particularly when surgical services are centralized.

My questions are the following. First, what is the Ross implantation technique of choice? Second, do you believe the Ross procedure is a legitimate contender in the current era of excellent outcomes with minimally invasive aortic valve replacement? Finally, although not the focus of your review, do you have any echocardiographic data about autograft or homograft abnormalities in patients who are "on the way" to reoperation?

Thank you to the Association for the privilege of this discussion and congratulations on the remarkable results.

Dr Charitos. Thank you very much. These are very pertinent questions. The Ross technique of choice is more or less a matter of debate. Obviously I am biased toward the SC technique. I come from Luebeck; Professor Sievers has probably the most extensive experience with the SC technique. I do believe that the Ross procedure should be performed with the SC technique. This seems logical. We have now more than 600 patients with a complete follow-up rate of $98 \%$. We know exactly what happens to all our patients. The SC technique seems to be technically more demanding; one should know which items one should pay special attention to and which to avoid during the procedure, but the SC technique does provide more robust results.

Some surgeons might prefer other techniques, such as the root replacement technique or root replacement with reinforcement. Some prominent root replacement series have been published, with very good results. However, in general and in the multicenter Ross registry, the root replacement technique without reinforcement has generally underperformed, and I think the data are consistent that the SC provides the best and the most robust results in the long term.

Your second question has to do with minimally invasive aortic valve replacement in this era. Minimally invasive aortic valve replacement does not offer many advantages for the 20-, 30-, or 35-year-old patient. Perhaps cosmetically; however, the problem of valve choice in the patient who is 20 or 25 years old does not depend on the type of surgical access.

The problem these patients face is mainly from the type of prosthesis. If one implants a biologic valve in a 20 -year-old patient, one will probably see the patient again in 5 to 7 years. However; a mechanical valve will change the patient's lifestyle, and the patient will face a certain lifetime risk of significant complications. Thus, the type of surgical access for aortic valve replacement in young patients I do not believe has a major effect for a young patient with aortic valve disease, other than, perhaps, cosmetic implications.

And the third question?

Dr Dearani. Whether you have any information about echocardiographic data on the hemodynamic abnormalities in patients that many have but who have not yet required reoperation.

Dr Charitos. This is also a very pertinent question. We do have echocardiographic data. There are patients who have some autograft or homograft dysfunction that might eventually require reoperation but who have, at least for now, not reached the indications for reoperation. The indications for reoperation are much more clear with the autograft and slightly more hazy for the homograft, but certainly we had patients in the study with valve dysfunction at risk of reoperation.

Dr Azhar Hossain (Miami, Fla). My question is regarding the bicuspid valve in the young adult, say 20 years old, with severe regurgitation. Would you recommend the Ross procedure for that patient? If so, what procedure would you choose, the classic Ross, which is the SC, or the root replacement?

Dr Charitos. A bicuspid aortic valve is not a contraindication for the Ross procedure. Patients with pure aortic regurgitation do have a greater risk of reoperation; the hazard ratio is about 2.4 to 2.9. But we do not consider patients with a bicuspid aortic valve to have a contraindication to the Ross procedure. Currently, I think the tendency is to repair these valves, but certainly we do not regard a bicuspid aortic valve as a contraindication for the Ross procedure.

The choice of procedure is more or less surgeon specific. We have found that if a center uses 1 specific technique, it usually sticks to that technique. Whether the surgeon will perform additional interventions, for example, to stabilize the aortic annulus or the sinotubular junction in patients with pure aortic insufficiency who have some malformation of the aortic root, this is something one must decide in the operating room. But the choice of technique is mostly surgeon specific.

Dr Hossain. Thus, in other words, you are not concerned that in a bicuspid aortic valve, there is additional risk of root dilatation if you do a root replacement as opposed to an SC procedure?

Dr Charitos. No. We have extensively studied the effects of bicuspid aortic valve in terms of aortic insufficiency and dilatation of the aortic root. We published these findings about 3 or 4 years ago. We have found no clinically significant difference in 
terms of root dilatation or progression of aortic insufficiency in patients with a bicuspid aortic valve, irrespective of the technique.

Dr Hossain. I was referring to the pulmonary autograft that you are going to use in the aortic position. That has the same disease as the native aortic root, which has been reported by many well-published investigators. Thus, if you use a pulmonary autograft, which has a tendency to undergo dilatation, would you still use root replacement, as opposed to the SC, in a Ross procedure, which is the classic Ross?

Dr Charitos. I do not think there is much evidence that the pulmonary autograft in the aortic position in a patient with a bicuspid valve has a greater failure rate. There is only 1 report from the team of Tirone David stating that in some patients with bicuspid aortic valves there are some histologic abnormalities, but that is a very long way to proving that if this patient has a pulmonary autograft in the bicuspid aortic valve position, that the autograft will fail. If one wants to determine whether in a patient with bicuspid aortic valve the autograft fails to a greater extent, one must investigate exactly that assumption. One cannot state that because we have seen some histologic abnormalities in the pulmonary valve of some bicuspid aortic valve patients, then implanting this pulmonary autograft in the aortic position would be the cause of the failure. That is a very big leap.

We have extensively analyzed the effect of bicuspid valves and we have seen no clinically significant influence of the bicuspid aortic valve on the durability of the autograft.

Dr Andre Vincentelli (Lille, France). Congratulations for your outstanding series. What was the proportion of patients receiving the SC technique coming from Leubeck in your series?

Dr Charitos. I think I can say we contributed most of the patients treated with the SC technique. From the 750 patients in the Ross registry treated with the SC technique, about 580 were from Leubeck.

Dr Vincentelli. This experience seems to be quite unique in Leubeck and the very good results with the SC technique that you have reported remain hardly reproducible elsewhere. In our series of 394 patients undergoing a Ross operation, we have used the modified root inclusion with a Dacron Valsalva prostheses in 69 patients since 2003. We had no reoperation with this technique that has become routinely used since April 2010 in our institution. Do you have such experience?

Dr Charitos. We have few patients with Dacron root inclusion and 30 patients with the miniroot inclusion technique in the Ross registry. That was too small a population to analyze it separately. Thus, we included the miniroot inclusion patients with the SC patients. Most of these patients with the SC technique were patients in whom the noncoronary sinus was preserved. So it could be considered is a root-preserving technique; the SC technique or the miniroot technique is a type of native root-preserving technique.

Dr Nicholas T. Kouchoukos (St. Louis, Mo). Just a follow-up to Dr Dearani's questions. Regarding the SC technique, you have a large experience with this, and it is fairly clear that the failure rates will be different between the SC technique and the root replacement technique, and he asked you about echocardiographic follow-up. Have you seen increases in the degree of aortic regurgitation with the SC technique in patients who have not yet required reoperation, because this is an important consideration. My second question relates to the techniques of preservation of the homograft. Were different techniques used among the different institutions? Were these available commercially or were they prepared in your own hospital?

Dr Charitos. Regarding your first question, we recently published our experience with 200 patients with more than 10 years of follow-up, and we had complete echocardiographic data available. We follow-up every patient; we examine every patient, every year. We have a complete follow-up rate of more than $98 \%$ in Luebeck, so we know exactly what happens to the patients.

In the SC technique, we have not seen this gradual increase in the dimensions and aortic regurgitation one sees with the root replacement technique. When the SC technique fails, it is usually abrupt and mostly due to isolated leaflet problems, cusp prolapse or cusp tear, or endocarditis. Nevertheless, there are few patients with moderate aortic regurgitation who might may require reoperation in the future.

Regarding your second question, the evaluation of the homograft is a very complex topic. There are many factors that could potentially have an influence. The factors we have presented were factors influencing, not the function of the homograft, but the incidence of reoperation as an event. Drs Mokhles and Takkenberg are analyzing the homograft data with the cooperation of Dr Blackstone. We hope we will have some high-quality data and results on the durability of the homograft and homograft function and the risk for deterioration within this year.

But I just want to say that the evaluation of the homograft is a very, very complex topic. 